\title{
Original
}

\section{Biochemical composition of carious dentin and different layers of sound dentin}

\author{
Larissa Magnus, Marisa Maltz, Caren Bavaresco, Lucelen F. Bastos, \\ and Lina N. Hashizume
}

\begin{abstract}
Department of Preventive and Social Dentistry, Faculty of Dentistry, Federal University of Rio Grande do Sul, Porto Alegre, RS, Brazil
\end{abstract}

(Received October 25, 2012; Accepted March 21, 2013)

\begin{abstract}
The aim of this study was to evaluate the concentrations of calcium (Ca), inorganic phosphate $\left(P_{i}\right)$ and fluoride $(F)$ in carious dentin and in different layers of sound dentin. The samples examined were 52 permanent teeth (26 sound and 26 carious), which were subjected to two experiments to assess the mineral content of: 1) two layers (internal and external) of sound dentin and 2) sound and carious dentin. $C a$ and $P_{i}$ were analyzed using a colorimetric method with arsenazo III (C22H18As2N4O14S2) and molybdate reagents, and $F$ was analyzed using a specific electrode. A non-parametric test, the MannWhitney test, was used to verify differences between groups. Sound dentin showed a higher concentration of fluoride in the internal layer than in the external layer $(P=0.03)$, but no inter-layer differences in $\mathrm{Ca}$ or $P_{i}$ concentration were evident. Lower concentrations of $\mathrm{Ca}, \mathrm{P}_{\mathrm{i}}$ and $\mathrm{F}$ were observed in carious dentin than in sound dentin $(P<0.05)$. The results of this study suggest that the internal layer of sound dentin has a higher fluoride content than the external layer, and that carious dentin has lower concentrations of $\mathrm{Ca}, \mathrm{P}_{\mathrm{i}}$ and $F$ than sound dentin.
\end{abstract}

(J Oral Sci 55, 133-137, 2013)

Keywords: dental caries; minerals; dentin; permanent dentition.

Correspondence to Dr. Lina Naomi Hashizume, Department of Preventive and Social Dentistry, Faculty of Dentistry, Federal University of Rio Grande do Sul, Rua Ramiro Barcelos, 2492, Bom Fim, Porto Alegre, CEP: 90035-003 RS, Brazil

Fax:+55-51-3308-5002 E-mail: lhashizume@yahoo.com

\section{Introduction}

The process of dental caries results in demineralization of hard dental tissues, leading to a considerable reduction in their mineral content (1-6). Calcium, inorganic phosphate and fluoride are the main constituents of the mineral phase of dentin (2,7-9). The concentrations of these ions play an important role in the processes of demineralization and remineralization of dentin (3-4,10-12).

Several attempts have been made to analyze the mineral composition of different dentin layers (2-4). It is important to study the distribution of minerals in hard tissues and the relationship between the mineral content and pathologic processes. Previous studies of the inorganic phosphate and calcium contents of dentin have involved biochemical analyses $(10,13)$. More recently, however, different methodologies such as energy-dispersive X-ray analysis $(2,4,13-14)$, neutron activation analysis $(15,16)$, atomic absorption (7-8) and laser (17-18) spectrometry have been employed. Biochemical analysis is able to detect small amounts of $\mathrm{Ca}, \mathrm{P}_{\mathrm{i}}$ and $\mathrm{F}$, and has been widely used in studies of biofilm, dental enamel and biofilm fluid (19-24). Biochemical studies of dentin involved only a few samples and did not analyze the concentrations of $\mathrm{Ca}, \mathrm{P}_{\mathrm{i}}$ and $\mathrm{F}$ together. Accordingly, the results cannot be generalized with confidence to the demineralization of dentin during the process of caries.

The aim of the present study was to evaluate, using biochemical analysis, the concentrations of calcium, inorganic phosphate and fluoride in different mineralized layers of sound dentin, and the mineral content of both sound and carious dentin, in permanent teeth. 

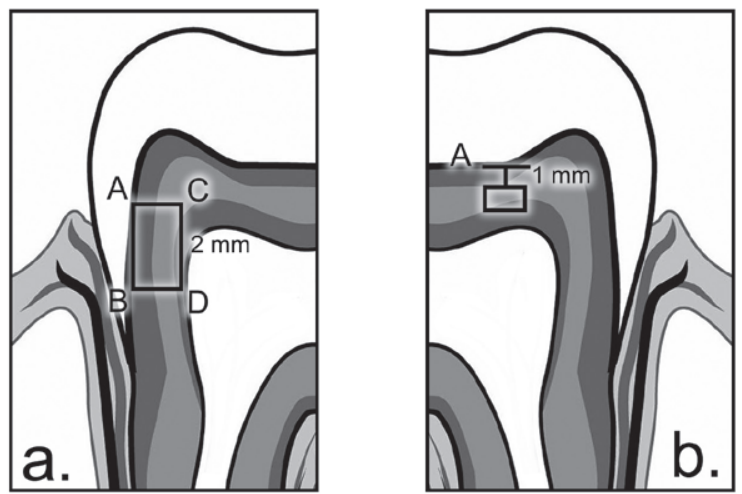

Fig. 1 Schema showing preparation of sound dentin specimens for experiment 1 (mesial halves) and experiment 2 (distal halves). a) Limits of the dentin blocks used in experiment 1: external limit (enamel junction, A-B), internal limit (dentin-pulp junction, $\mathrm{C}$-D), occlusal limit (A-C) and cervical limit (B-D). b) The blocks used in experiment 2 were collected from the occlusal surface 1 $\mathrm{mm}$ below the enamel-dentin junction (A).

\section{Materials and Methods}

To evaluate the concentrations of calcium, inorganic phosphate and fluoride in dentin (sound and carious), two experiments were carried to assess the mineral content of: sound dentin in different layers (experiment 1) and both sound and carious dentin (experiment 2).

\section{Samples}

In both experiments, the samples of sound dentin were obtained from molar teeth supplied by the Human Tooth Bank of the Faculty of Dentistry, Federal University of Santa Maria, RS, Brazil. The teeth had been stored in $2 \%$ formalin solution after extraction. The sound molars, without any damage to the crown portion, had been extracted due to periodontal disease, or for orthodontic or prosthetic reasons. The donors were all adults, of both genders, living in the city of Porto Alegre, RS, Brazil.

The carious human dentin samples were obtained from patients treated at the dental clinic of the Faculty of Dentistry, Federal University of Rio Grande do Sul. The samples were collected from teeth before restorative treatment. These teeth were not extracted; only samples of carious dentin were collected.

The total sample comprised 52 permanent molar teeth: 11 first molars, 13 second molars and 28 third molars. This study was approved by the Ethics Committee of the Faculty of Dentistry, Federal University of Rio Grande do Sul, Brazil (protocol number 288/08).

The sample size was based on a pilot study considering a statistical power of 0.8 and a level of significance of 0.05 . A total of 24 samples for calcium and 13 samples for analysis of fluoride and inorganic phosphate were found. Considering a possible loss of $8 \%$, the sample size was 26 molar teeth for each analysis.

\section{Specimen preparation}

The crowns of 26 sound molar teeth were divided into two halves (mesial and distal) with a low-speed diamond saw machine (Buehler, Lake Bluff, IL, USA). The mesial halves were used in experiment 1 and the distal halves in experiment 2 (Fig. 1).

In experiment 1 , blocks of dentin were obtained from the proximal surface within the following limits: the enamel-dentin junction and dentin-pulp junction (lateral limits), where two lines were drawn perpendicular to the lateral limits - a line from the pulp horn in the direction of the enamel-dentin junction (occlusal limit) and a line $2 \mathrm{~mm}$ below the occlusal limit (cervical limit) (Fig. 1a). The blocks were cut into two halves (external and internal blocks) with a low-speed diamond saw machine.

In experiment 2, blocks of sound dentin $\left(1 \mathrm{~mm}^{3}\right)$ were obtained from the occlusal surface, $1 \mathrm{~mm}$ below the enamel-dentin junction (Fig. 1b). The blocks were collected using a low-speed diamond saw machine and a wafering blade. Prior to cutting, a caliper rule was used to measure the dimensions for cutting the dentin block (1 $\times 1 \times 1 \mathrm{~mm}$ ).

Carious dentin samples were obtained from occlusal caries lesions before restorative treatment. Each treated tooth was isolated with a rubber dam. Before collection of carious dentin, the superficial necrotic disorganized soft dentin was removed employing a visual and tactile approach. The cavity was washed with saline and dried with sterile swabs, and material was sampled for biochemical analysis. An endodontic file was used as a reference to measure the depth of the carious cavity. Sound and carious dentin samples were obtained at a similar distance from the pulp.

After sectioning and collection, all samples were frozen at $-20^{\circ} \mathrm{C}$ for subsequent analysis.

\section{Biochemical analysis}

All the samples (sound and carious dentin) were subjected to the same biochemical procedures. The samples were dehydrated for $24 \mathrm{~h}$ at $37^{\circ} \mathrm{C}$, manually ground, and then weighed (Sartorius, Göttingen, Germany). For $\mathrm{Ca}, \mathrm{P}_{\mathrm{i}}$ and $\mathrm{F}$ extraction from the dentin, $0.5 \mathrm{M}$ hydrochloric acid $(\mathrm{HCl})$ was added to the microtubes $(0.5 \mathrm{~mL} \mathrm{HCl} /$ $\mathrm{mg}$ dry weight dentin) containing the samples. After 3 $\mathrm{h}$ of constant agitation at room temperature, the samples were centrifuged for $10 \mathrm{~min}$ at 14,000 rpm (Eppendorf, Hamburg, Germany) and the supernatant was retained 
Table 1 Concentrations of calcium, inorganic phosphate and fluoride in the internal and external layers of dentin

\begin{tabular}{|c|c|c|c|c|c|c|c|c|}
\hline & \multirow[b]{2}{*}{$n$} & \multicolumn{3}{|c|}{$\begin{array}{l}\text { Internal layer } \\
\text { Percentiles }\end{array}$} & \multicolumn{3}{|c|}{$\begin{array}{c}\text { External layer } \\
\text { Percentiles }\end{array}$} & \multirow[b]{2}{*}{$P$} \\
\hline & & 25 & 50 & 75 & 25 & 50 & 75 & \\
\hline $\begin{array}{l}\text { Calcium } \\
(\mu \mathrm{mol} \mathrm{Ca} / \mathrm{mg} \text { dentin })\end{array}$ & 26 & 0.20 & 0.28 & 1.11 & 0.19 & 0.28 & 0.86 & 0.52 \\
\hline $\begin{array}{l}\text { Inorganic phosphate } \\
\left.\text { ( } \mu \mathrm{mol} \mathrm{P}_{\mathrm{i}} / \mathrm{mg} \text { dentin }\right)\end{array}$ & $23 *$ & 0.27 & 0.50 & 1.02 & 0.25 & 0.30 & 0.97 & 0.64 \\
\hline $\begin{array}{l}\text { Fluoride } \\
\text { (ppmF) }\end{array}$ & 26 & 2299.00 & 5379.00 & 12777.00 & 1218.00 & 2879.00 & 7196.00 & 0.03 \\
\hline
\end{tabular}

*In three samples the amount of $P_{i}$ could not be determined

Mann-Whitney non-parametric test

Table 2 Concentrations of calcium, inorganic phosphate and fluoride in carious and sound dentin

\begin{tabular}{|c|c|c|c|c|c|c|c|c|}
\hline & \multirow[b]{2}{*}{$n$} & \multicolumn{3}{|c|}{$\begin{array}{c}\text { Carious dentin } \\
\text { Percentiles }\end{array}$} & \multicolumn{3}{|c|}{$\begin{array}{l}\text { Sound dentin } \\
\text { Percentiles }\end{array}$} & \multirow[b]{2}{*}{$P$} \\
\hline & & 25 & 50 & 75 & 25 & 50 & 75 & \\
\hline $\begin{array}{l}\text { Calcium } \\
(\mu \mathrm{mol} \mathrm{Ca} / \mathrm{mg} \text { dentin})\end{array}$ & $25^{*}$ & 0.09 & 0.18 & 0.53 & 0.16 & 0.32 & 0.62 & 0.04 \\
\hline $\begin{array}{l}\text { Inorganic phosphate } \\
\text { ( } \mu \mathrm{mol} \mathrm{P}_{\mathrm{i}} / \mathrm{mg} \text { dentin) }\end{array}$ & 26 & 0.04 & 0.07 & 0.13 & 0.10 & 0.14 & 0.25 & 0.00 \\
\hline $\begin{array}{l}\text { Fluoride } \\
\text { (ppmF) }\end{array}$ & 26 & 289.00 & 967.00 & 2283.00 & 1197.00 & 2727.00 & 5232.00 & 0.01 \\
\hline
\end{tabular}

*In one sample the amount of Ca could not be determined

Mann-Whitney non-parametric test

for $\mathrm{Ca}, \mathrm{P}_{\mathrm{i}}$ and $\mathrm{F}$ determination. Inorganic phosphate and calcium were determined colorimetrically using the reagents arsenazo III and molybdate, respectively (17,19-21). Fluoride measurement was performed using a fluoride-sensitive electrode (Orion 9609, Orion Research Inc., Beverly, MA, USA) connected to an ion analyzer (Procyon Instrumentos Científicos, São Paulo, São Paulo, Brazil) (17,19,21-22). The results were expressed as micromoles per milligram of dentin ( $\mu \mathrm{mol} / \mathrm{mg}$ dentin) for $\mathrm{Ca}$ and $\mathrm{P}_{\mathrm{i}}$, and in parts per million (ppm) for $\mathrm{F}$.

\section{Statistical analysis}

A non-parametric test, the Mann-Whitney test, was used to verify differences in calcium, inorganic phosphate and fluoride concentrations in different layers of dentin and for comparison between sound and carious dentin. The statistical analyses were done using the SPSS software package, version 17.0, for Windows (SPSS, Chicago, IL, USA) at a significance level of 0.05 .

\section{Results}

Table 1 shows the concentrations of $\mathrm{Ca}, \mathrm{P}_{\mathrm{i}}$ and $\mathrm{F}$ in different layers of dentin. For calcium and inorganic phosphate, no differences in concentration were observed between the internal and external layers. Only for fluoride did the internal layer show a higher concentration than the external layer $(P=0.03)$.

The concentrations of calcium, inorganic phosphate and fluoride in sound and carious dentin are expressed in Table 2. Carious dentin had lower concentrations of calcium, inorganic phosphate and fluoride than sound dentin $(P<0.05)$.

\section{Discussion}

The present study assessed the inorganic composition of sound and carious dentin of permanent human teeth using biochemical analysis.

The concentrations of $\mathrm{Ca}$ and $\mathrm{P}_{\mathrm{i}}$ were similar in the internal and external layers of dentin, while a higher concentration of fluoride was observed in the internal layer than in the the external layer. There was considerable variation in the concentrations of calcium, inorganic phosphate and fluoride among the analyzed samples. Previous studies have reported the composition of minerals in sound dentin $(1,15,25)$. The concentrations of calcium and inorganic phosphate may vary among individuals according to age, gender, location and environmental factors $(7,15,24,25)$. The variation of mineral concentrations observed in the present study was similar to that already noted in other studies $(7,13,15)$. 
Angker et al. (3), using back-scattered electron (BSE) imaging, showed that the deep circumpulpal dentin (accounting for around 15\% of the circumpulpal dentin) had a decreased mineral content. However, this small difference in mineral content observed by Angker et al. (3) was not noted by Levine (13), or in the present study. This difference in results could have been attributable to sample collection methodology. In the present study, each dentin sample was divided into two halves, whereas in the study by Angker et al. (3) the measurements were done continuosly with a working distance of $10 \mathrm{~mm}$. The small portion (15\% of the circumpulpal dentin) with a lower mineral content observed by BSE imaging accounted for only a small part of the internal layer we observed. Therefore, such small differences in mineral content could not be measured in the present study.

The great variation in the amount of fluoride observed in sound dentin among the samples has also been noted by others. However, the concentration of fluoride observed in the present study was higher than that in other studies done in the 1970s $(7-8,15)$, perhaps due to the increased availability of fluoride. Furthermore, our samples were obtained from an area with a fluoridated water supply where there was access to fluoride dentifrice, whereas the samples used in other studies $(7-8,15)$ were collected from non-fluoridated areas where access to fluoride dentifrice was probably limited. Higher concentrations of fluoride were observed in the internal dentin layer than in the external layer. Weatherell et al. (26) also observed an increase in fluoride concentration from the dentin-enamel junction toward the pulp chamber.

Carious dentin has a lower mineral content than sound dentin $(1-4,13)$. In the present study, significantly lower amounts of calcium and inorganic phosphate were detected in carious dentin than in sound dentin. These results are consistent with the pathology of dental caries, which is characterized by mineral loss $(1-4,13)$.

In dental enamel the concentrations of fluoride in carious teeth are higher than in sound teeth, due to a remineralization process that allows the formation of fluorapatite $(27,28)$. In the present study, carious dentin had a lower concentration of fluoride than sound dentin. The carious dentin was collected from carious cavities with intact walls, which showed no destruction of the proximal wall, and thus were not fully exposed to the oral environment. These environmental conditions could explain the lower amount of fluoride due to the predominant demineralization process occurring in the carious dentin located at the bottom of the cavity.

The results of this study suggest that the internal layer of sound dentin has a higher fluoride content than the external layer, and that carious dentin has lower concentrations of $\mathrm{Ca}, \mathrm{P}_{\mathrm{i}}$ and $\mathrm{F}$ than sound dentin. Further studies examining the effects of different treatments on carious dentin using the same methodology should be conducted. The present results are considered to provide useful reference data.

\section{References}

1. Arnold WH, Konopka S, Gaengler P (2001) Qualitative and quantitative assessment of intratubular dentin formation in human natural carious lesions. Calcif Tissue Int 69, 268-273.

2. Arnold WH, Konopka S, Kriwalsky MS, Gaengler P (2003) Morphological analysis and chemical content of natural dentin carious lesion zones. Ann Anat 185, 419-424.

3. Angker L, Nockolds C, Swain MV, Kilpatrick N (2004) Quantitative analysis of the mineral content of sound and carious primary dentin using BSE imaging. Arch Oral Biol 49, 99-107.

4. Arnold WH, Gaengler P (2007) Quantitative analysis of the calcium and phosphorus content of developing and permanent human teeth. Ann Anat 189, 183-190.

5. Cochrane NJ, Shen P, Byrne SJ, Walker GD, Adams GG, Yuan Y et al. (2012) Remineralisation by chewing sugar-free gums in a randomised, controlled in situ trial including dietary intake and gauze to promote plaque formation. Caries Res 46, 147-155.

6. Charadram N, Farahani RM, Harty D, Rathsam C, Swain MV, Hunter N (2012) Regulation of reactionary dentin formation by odontoblasts in response to polymicrobial invasion of dentin matrix. Bone 50, 265-275.

7. Derise NL, Ritchey SJ (1974) Mineral composition of normal human enamel and dentin and the relation of composition to dental caries. II. Microminerals. J Dent Res 53, 853-858.

8. Derise NL, Ritchey SJ, Furr AK (1974) Mineral composition of normal human enamel and dentin and the relation of composition to dental caries. I. Macrominerals and comparison of methods of analyses. J Dent Res 53, 847-852.

9. Angker L, Swain MV, Wong L, Sissons C (2011) The effects of fluoride and mineralising treatments on plaque microcosm $\mathrm{Ca}, \mathrm{P}$ and $\mathrm{F}, \mathrm{pH}$ responses and cariogenicity. N Z Dent J 107, 12-18.

10. Eidelman E, Finn SB, Koulourides T (1965) Remineralization of carious dentin treated with calcium hydroxide. J Dent Child $32,218-225$.

11. Xu Z, Neoh KG, Lin CC, Kishen A (2011) Biomimetic deposition of calcium phosphate minerals on the surface of partially demineralized dentine modified with phosphorylated chitosan. J Biomed Mater Res B Appl Biomater 98, 150-159.

12. Weir MD, Moreau JL, Levine ED, Strassler HE, Chow LC, Xu HH (2012) Nanocomposite containing $\mathrm{CaF}(2)$ nanoparticles: thermal cycling, wear and long-term water-aging. Dent Mater $28,642-652$

13. Levine RS (1973) The differential inorganic composition of dentin within active and arrested carious lesions. Caries Res 7, 245-260. 
14. Massara ML, Alves JB, Brandão PR (2002) Atraumatic restorative treatment: clinical, ultrastructural and chemical analysis. Caries Res 36, 430-436.

15. Lakomaa EL, Rytömaa I (1977) Mineral composition of enamel and dentin of primary and permanent teeth in Finland. Scand J Dent Res 85, 89-95.

16. Chamberlain M, Gräfe JL, Aslam, Byun SH, Chettle DR, Egden LM et al. (2012) In vivo quantification of bone-fluorine by delayed neutron activation analysis: a pilot study of handbone-fluorine levels in a Canadian population. Physiol Meas 33, 375-384.

17. Moshonov J, Stabholz A, Bar-Hilel R, Peretz B (2005) Chemical analysis and surface morphology of enamel and dentin following $9.6 \mathrm{mu} \mathrm{CO} 2$ laser irradiation versus high speed drilling. J Dent 33, 427-432.

18. Markowitz K, Stenvall RM, Graye M (2012) The effect of distance and tooth structure on laser fluorescence caries detection. Oper Dent 37, 150-160.

19. Vogel GL, Chow LC, Brown WE (1983) A microanalytical procedure for the determination of calcium, phosphate and fluoride in enamel biopsy samples. Caries Res. 17, 23-31.

20. Pearce EI, Hancock EM, Gallagher IH (1984) The effect of fluorhydroxyapatite in experimental human dental plaque on its $\mathrm{pH}$, acid production and soluble calcium, phosphate and fluoride levels following glucose challenge. Arch Oral Biol 29, 521-527.
21. Vogel GL, Carey CM, Chow LC, Tatevossian A (1990) Microanalysis of plaque fluid from single-site fasted plaque. J Dent Res 69, 1316-1323.

22. Tenuta LM, Del Bel Cury AA, Bortolin MC, Vogel GL, Cury JA (2006) $\mathrm{Ca}, \mathrm{Pi}$, and $\mathrm{F}$ in the fluid of biofilm formed under sucrose. J Dent Res 85, 834-838.

23. Vogel GL (2011) Oral fluoride reservoirs and the prevention of dental caries. Monogr Oral Sci 22, 146-157.

24. Ricomini Filho AP, Tenuta LM, Fernandes FS, Calvo AF, Kusano SC, Cury JA (2012) Fluoride concentration in the top-selling Brazilian toothpastes purchased at different regions. Braz Dent J 23, 45-48.

25. Adegboye AR, Fiehn NE, Twetman S, Christensen LB, Heitmann BL (2010) Low calcium intake is related to increased risk of tooth loss in men. J Nutr 140,1864-1868.

26. Weatherell JA, Deutsch D, Robinson C, Hallsworth AS (1977) Assimilation of fluoride by enamel throughout the life of the tooth. Caries Res 11, Suppl 1, 85-115.

27. Ekstrand KR, Ricketts DN, Kidd EA (1997) Reproducibility and accuracy of three methods for assessment of demineralization depth of the occlusal surface: an in vitro examination. Caries Res 31, 224-231.

28. Dawes C (2003) What is the critical pH and why does a tooth dissolve in acid? J Can Dent Assoc 69, 722-724. 